\title{
Description of transverse maxillary expansion in patients with bilateral cleft lip and palate undergoing singivoperiosteoplasty with alveolar bone graft. A preliminary study
}

\author{
N. Niez ${ }^{1,5}$, K. Nham ${ }^{1,3}$, B. Vi-Fane ${ }^{1,2,3,4}$ \\ 1 Dental surgeon \\ 2 Dentofacial orthopedics specialist \\ 3 MAFACE rare orofacial deformities reference center \\ 4 University lecturer - Hospital practitioner \\ 5 Fellow, Paris Hospitals
}

\section{ABSTRACT}

Cleft lip and palate (CLP) is one of the most common facial deformities. Treatment is long and complex, requiring a multidisciplinary team, including an orthodontist, who plays a prime role in ensuring that dental phenomena occur under the best possible conditions allowed by often unfavorable anatomy and growth and healing factors. Orthodontic preparation by maxillary expansion is a key step in management, mandatory ahead of gingivoperiosteoplasty and alveolar bone graft. Since 2000, Pr Vasquez's maxillofacial and plastic surgery team in the Necker Hospital (Paris, France) has used a treatment protocol involving alveolar cleft repair by gingivoperiosteoplasty and alveolar bone graft at 4-6 years of age.

Orthopedic mechanics induces not only strictly orthopedic effects but also orthodontic dento-alveolar compensation. In CLP, physiology is exceptional in that there is no median palatine suture between fragments, and it can be supposed that the behavior of surrounding structures during maxillary expansion differs from that is a classical patient.

We therefore undertook a radiologic study of the dento-alveolar phenomena accompanying preoperative orthodontic expansion in bilateral CLP patients, in a group selected from those jointly managed by $\operatorname{Pr} V a z q u e z ' s$ team and Dr Vi Fane's team in the Rothschild Hospital (Paris), under the auspices of the MAFACE rare diseases reference center.

\section{KEY WORDS}

Cleft lip and palate, maxillary expansion, gingivoperiosteoplasty, secondary alveolar bone graft 


\section{INTRODUCTION}

Cleft lip and palate (CLP) is a very heterogeneous clinical entity comprising congenital deformities of mixed genetic and environmental origin. It affects the orofacial region, with involvement of varying complexity of the lip, nose, alveolar region and hard and soft palate and is due to fusion defect in the embryonic buds occurring at 4-12 weeks' gestation.

\section{CHARACTERISTICS OF BILATERAL CLP}

\section{Anatomic characteristics}

CLP is associated with major deformity of the central face, with marked tissue discontinuity and labio-columellar defect ${ }^{16}$. Muscular discontinuity entails dynamic imbalance; all the cartilage structures to which the affected muscles insert gradually deform, being very malleable. Deformity thus involves both soft and hard
It is the most common facial abnormality. It may be isolated or associated with various deformity syndromes of varying complexity. Worldwide prevalence is estimated at about 1 per 700 live births ${ }^{17}$. Bilateral CLP is the rarest non-syndromic form, at only $10 \%$ of clefts; $20 \%$ of CLPs are bilateral. CLP shows 2:1 male predominance ${ }^{1}$.

tissue. The lip has a hypertrophic vermillion aspect. The nose is projected down and forward by the absence of columellar support and excessive traction by the orbicularis oris muscles on either side (Fig. 1). Premaxillary protrusion is the main characteristic of bilateral CLP, creating a very strong convexity profile, especially as the mandible is retrusive in infants. The volume of the

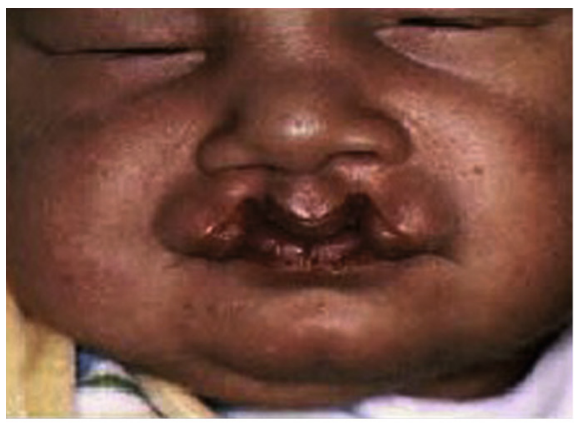

a

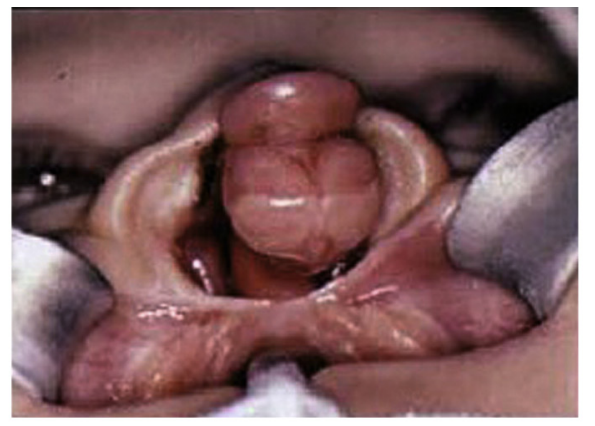

b

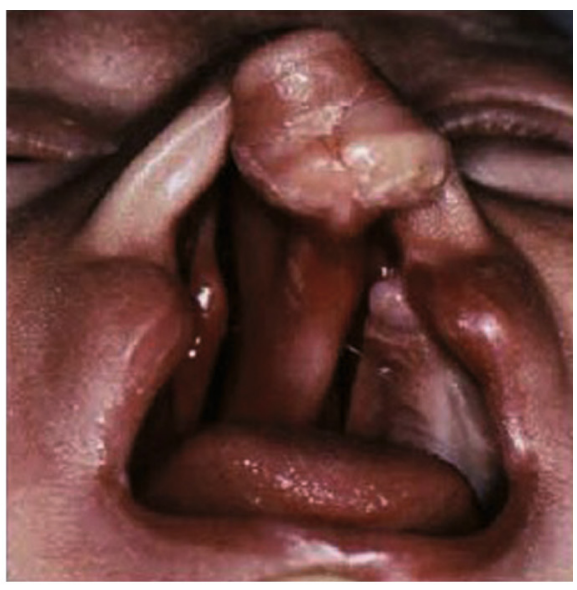

Figure 1

Various forms of bilateral CLP (from Morand and Raphael, 2004) ${ }^{16}$. a) Bilateral labial cleft. b) Bilateral labio-alveolar cleft. c) Bilateral total labio-alveolar-palatine cleft. 

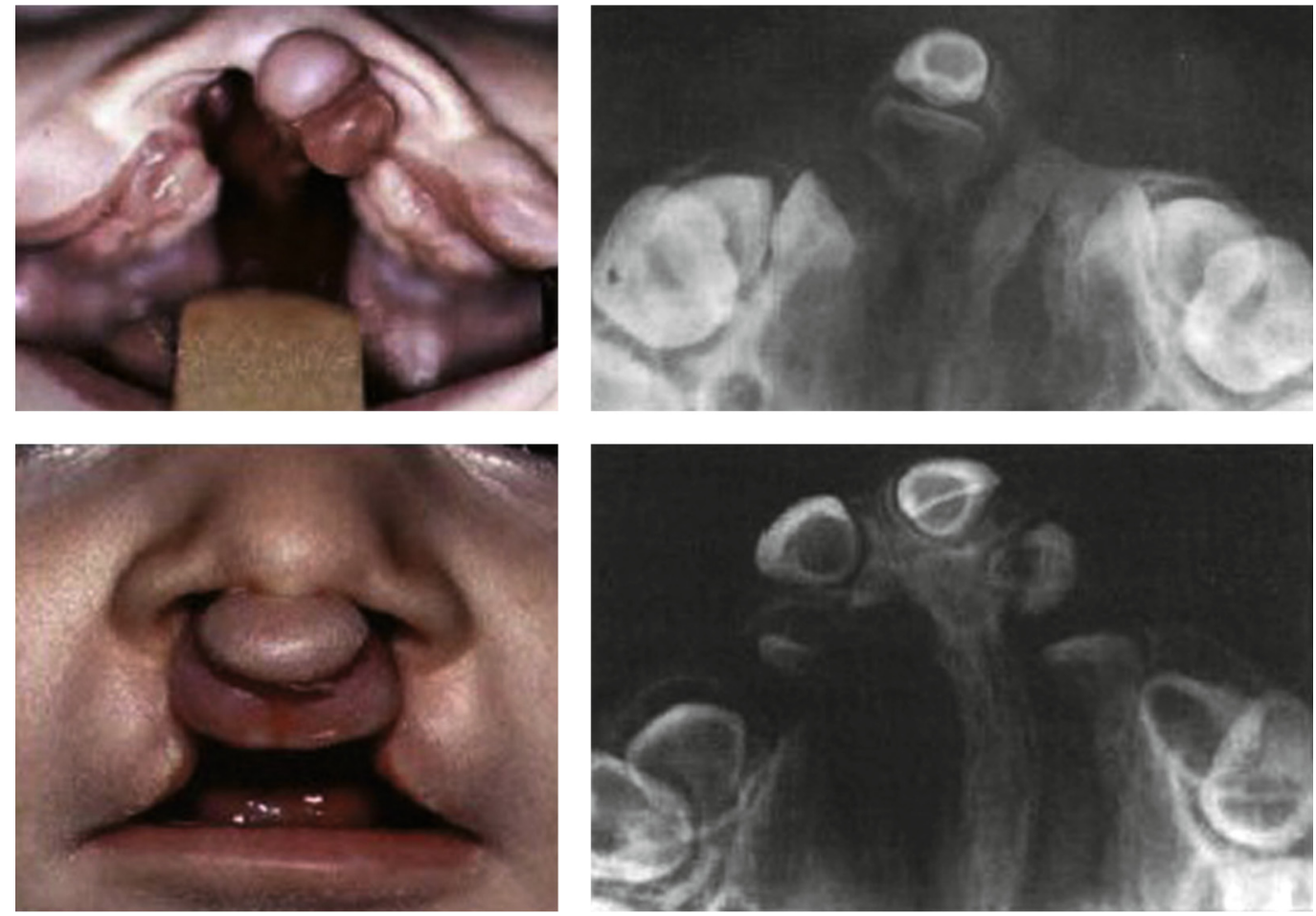

Figure 2

Influence of number of tooth germs on premaxillary volume (from Morand and Raphael, $2004)^{16}$.

premaxilla, and thus the number of tooth germs it contains, greatly affects local growth ${ }^{16}$ (Fig. 2).

\section{Skeletal characteristics}

Skeletal specificities are found in operated patients, resulting from a double influence: genetic (congenital) and the results of repair surgery (acquired), which inevitably has sideeffects, notably scarring ${ }^{2}$. Overall, there is little difference in the skullbase between bilateral CLP patients and healthy subjects, as it is remote from the deformity and uninvolved in surgery $^{27}$. In the maxilla, repair technique impact is mainly premaxillary. Cheiloplasty and rhinoplasty reposition the premaxilla; if it was originally rather protruding, it may then become retrusive. Moreover, it should be borne in mind that skeletal class III is common in CLP. Premaxillary repositioning tends to normalize the anteroposterior relation with the mandible ${ }^{33}$, which shows growth equivalent to that of healthy subjects. The direction of growth, on the other hand, tends to be divergent as mixed respiration is common, as is a low 
position of the tongue due to the reduced maxilla 27,33 .

\section{Dental characteristics}

Occlusion is severely disturbed by the disorganization of skeletal and alveolar support; dental abnormalities are much more frequent than in the general population. This is due to genetic, embryologic and anatomic interactions in the development of the lip, primary and secondary palate and tooth germs ${ }^{21,34}$. Abnormality concerns the number of germs, with more frequent agenesis of the lateral maxillary incisors and second maxillary premolars $6,12,31,34$ (Fig. 3), and the size, form and structure of teeth, but also organogenesis and eruption $^{6}$. Thus, the risk of included maxillary canine, for example, is 20 times as high as in the general population ${ }^{24}$. The severity of dental abnormality is agreed to correlate

\section{TREATMENT}

Surgical treatment of cleft has a 3-fold objective: restoring anatomy, respecting and optimizing growth, and restoring function $8,10,19,28,29$. It mobilizes a multidisciplinary team, which will develop its own protocol according to its therapeutic priorities. There are as many protocols as there are teams. The 2001 Eurocleft study found 194 different protocols among 201 European centers managing cleft 26. Respective results can only be assessed in the long term, so that there is at present no consensus as to treatment schedule or surgical technique. The protocol employed by with cleft severity. This is why bilateral cleft is especially involved. Concerning inter-arcade relations, Heidbuchel et al. ${ }^{13}$ found numerous differences from healthy subjects, with a tendency for aggravation after 7 years of age. Maxillary transverse insufficiency is more marked in the canines than molars, and worsens over time if not corrected (Fig. 4a). Consequently, inter-molar diameter is often reduced at the mandible, to compensate, and the anterior supraocclusion caused by the protruding fragment may limit mandibular growth. Anteroposteriorly, the arch angle is often reduced, leading to distal occlusion of the whole arch. Vertically, cover is often excessive, due to premaxillary repositioning (Fig. 4b). Occlusion is thus severely disturbed, with class II or III molar relations, anterior and lateral occlusion inversion, and crowding (Fig. 4c).

Pr Vazquez's team in the MAFACE rare diseases reference center is inspired by Talmant's functionalist approach, in which strictly nasal respiration is an essential aim to restore normal maxillary development ${ }^{20,28,29}$. Early uranoplasty also enables speech acquisition, with the aim of mastering language by primary school. Since 2000, the team's primary treatment schedule has been as follows:

- 3-6 months: veloplasty associated to 1-step bilateral cheilorhinoseptoplasty;

- 12 months: palate cleft closure. 


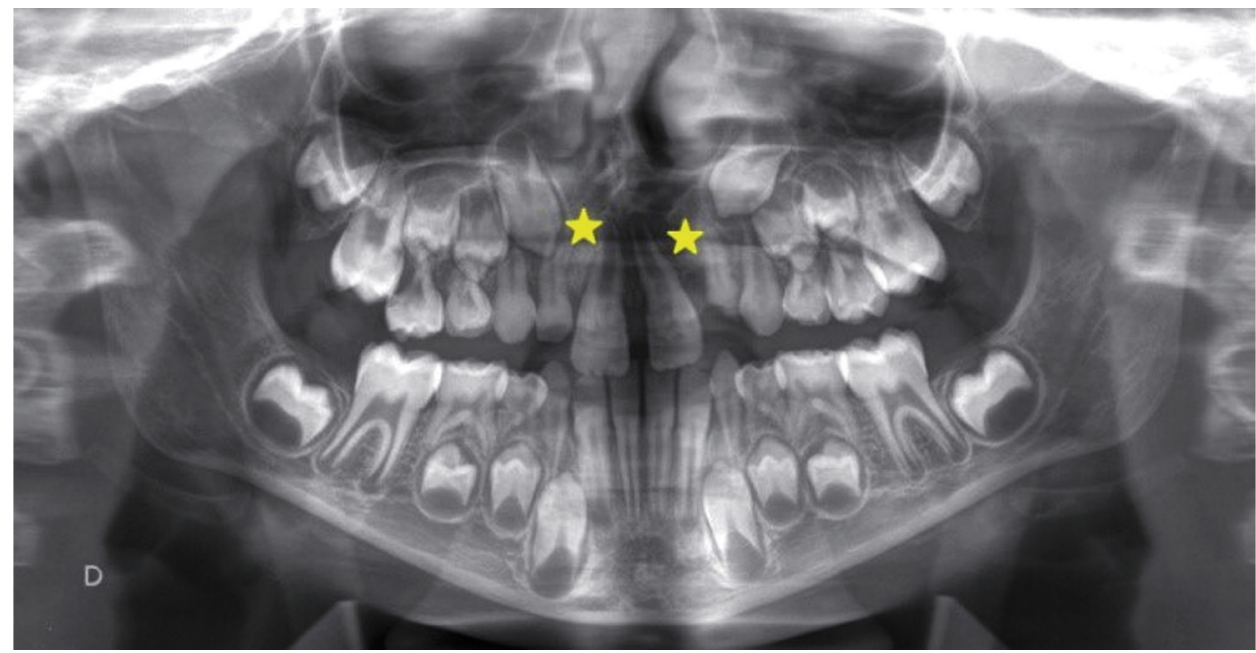

Figure 3

Panoramic radiograph showing lateral maxillary incisor agenesis in a 7 year-old reference center patient with bilateral CLP.

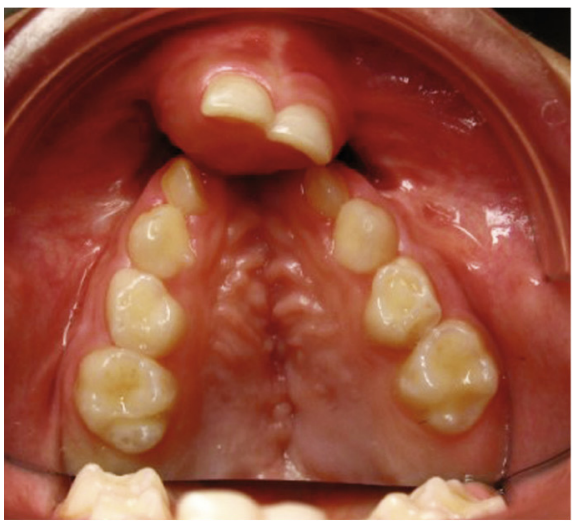

a

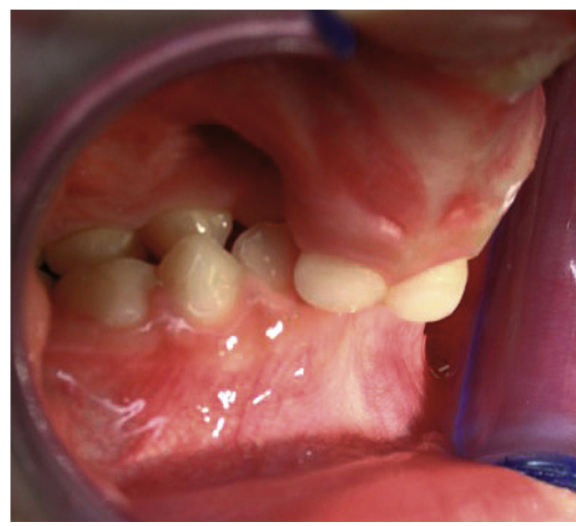

b

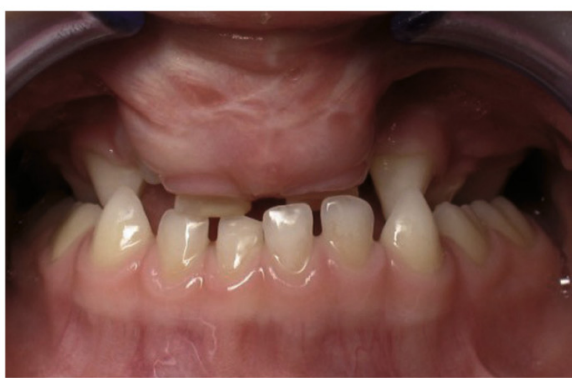

C

Figure 4

Inter-arcade abnormalities. a) Maxillary arch occlusion: lateral segment collapse and severely reduced inter-canine diameter in a reference center patient aged 4 years 8 months with bilateral CLP. b) Lingual inclination and increased premaxillary cover following cheiloplasty in the same patient. c) Bilateral anterior and posterior occlusion inversion in a reference center patient aged 4 years 8 months with bilateral CLP.

- 4-6 years: gingivoperiosteoplasty (GPP) with bone graft, in 2 steps in case of bilateral cleft (Fig. 5).

The final step in the protocol, and the focus of the present study, more particularly involves the orthodontist. Since Boyne and Sands' work in the 1970s, gingivoperiosteoplasty (GPP) has usually been associated to alveolar graft 71,29 . Several benefits are expected, and notably restoring alveolar bone continuity over and above mere tight closure, restoring an adequate bone support for dental 


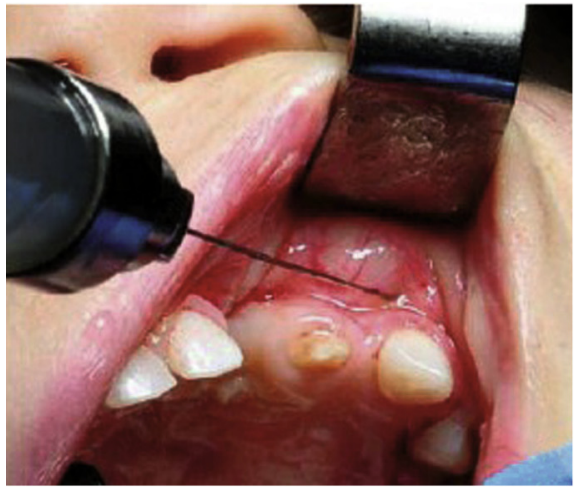

a

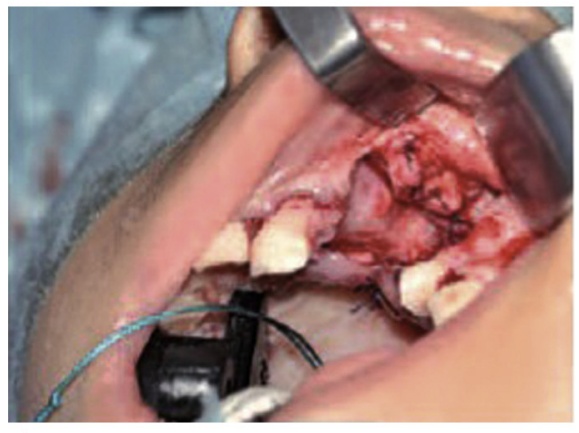

d

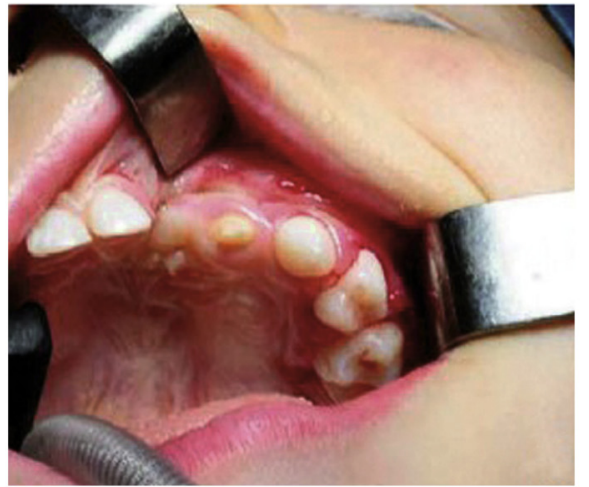

b

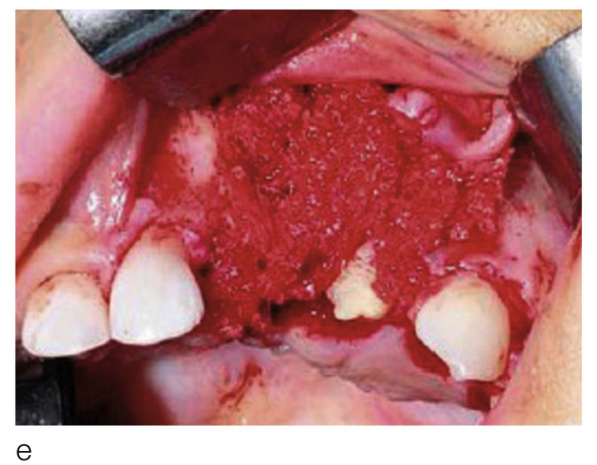

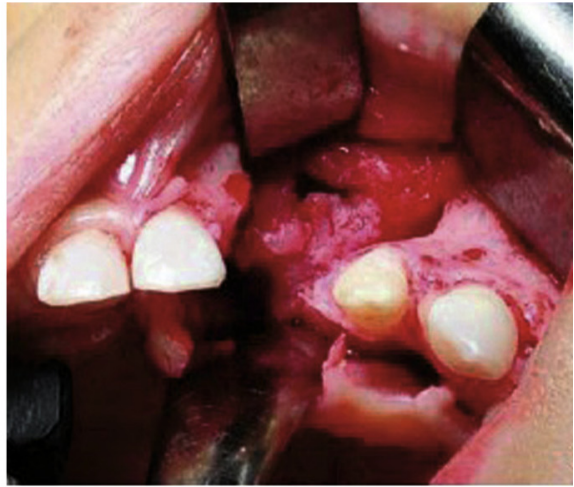

C

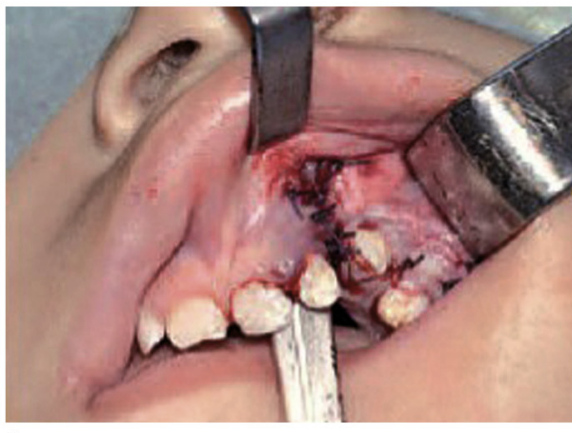

f

Figure 5

Gingivoperiosteoplasty in 2 cases of left unilateral CLP (from Talmant and Lumineau ${ }^{29}$ and Picard et al. ${ }^{20}$ ). a) Anesthesia. b) Incision at dental necks on vestibular side. c) Wide muco-periosteal detachment. d) Nasal and palatine suture. e) Cleft filling by iliac graft. f) Vestibular suture and postoperative aspect.

eruption, and maintaining arch width and preventing lateral fragment collapse. In the Necker Hospital maxillofacial and plastic surgery department's protocol, late primary GPP associates orthopedic treatment and bone graft $^{20}$. Initial orthopedic treatment (Fig. 6) of the deciduous teeth using a rapid maxillary expander on dental splints followed by a removable Quad-Helix appliance restores canine function, corrects endoocclusion, conserves lateral incisor space and restores piriform orifice width. GPP is then performed around the age of 4 years, when the cortical bone is dense enough to protect the tooth germs while the soft tissue is still very plastic ${ }^{29}$. The cleft space is filled by cancellous iliac graft. The orthopedic system (Quad-Helix appliance) is left as contention for about 6 months, during which time arch expansion may be continued if necessary as continuity has been restored. Graft volume and success are assessed on CT or CBCT (Cone Beam Computed Tomography).

\section{RATIONALE}

Maxillary expansion can be associated to several other results ${ }^{30}$ : median palatine suture opening (the ideal skeletal effect sought); 


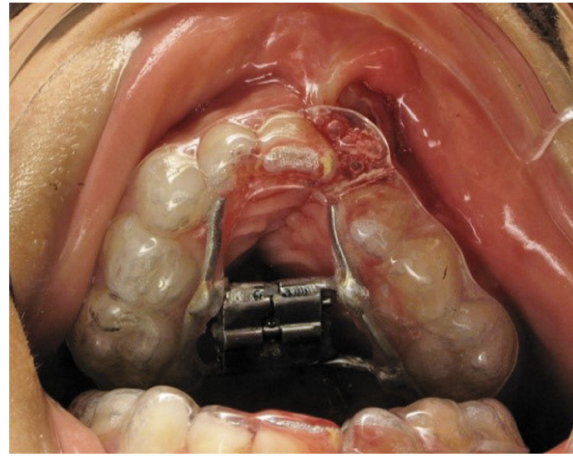

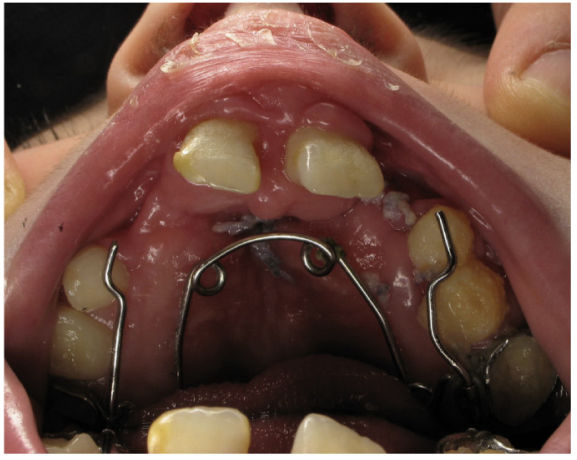

Figure 6

Reference center patient aged 6 years 6 months, with bilateral CLP. a) Orthopedic expansion by rapid maxillary expander on sealed dental splints. b) Contention phase with removable Quad-Helix appliance after left GPP.

appositional growth; vestibular inclination of the alveolar processes; and/ or vestibular tipping, or tooth egres$\operatorname{sion}^{3,14,30}$. Two types of expansion have been mainly studied: rapid expansion with rapid maxillary expander, reputed to have mainly skeletal impact, and slow expansion by QuadHelix, with mainly dento-alveolar impact ${ }^{30,14,15,22,23,3,18,25}$. Several studies have focused on alveolar growth, especially transverse growth. Björk and Skieller in particular made thorough studies of "normal" growth, especially using their endoosseous implant method ${ }^{4,5}$. They found that maxillary suture growth, like height and weight growth, shows peak acceleration in puberty. In the late 1970s, Dahl studied transverse maxillary growth, specifically in CLP9 . Growth rates in a sample of patients showed that all transverse dimensions of the face displayed the same puberty peak as found for overall growth, with the exception of maxillary width. Moreover, the expansion obtained in the suture was much less than in healthy subjects. There is in fact no suture in CLP patients, and maxillary structures are mainly displaced by the surrounding muscular structures ${ }^{9,14}$. This exceptional physiology raises the question of how transverse expansion is achieved after orthodontic/orthopedic preparation.

The objectives of the present study were therefore: (i) to determine whether expansion is achieved by compensatory dento-alveolar movement under coronary vestibular version alone, or by pure distal translation; (ii) to compare expansion in canine versus molar sectors; (iii) to determine whether there is transverse relapse and, if so, of what kind and intensity; and (iv) to study occlusion plane displacement. 


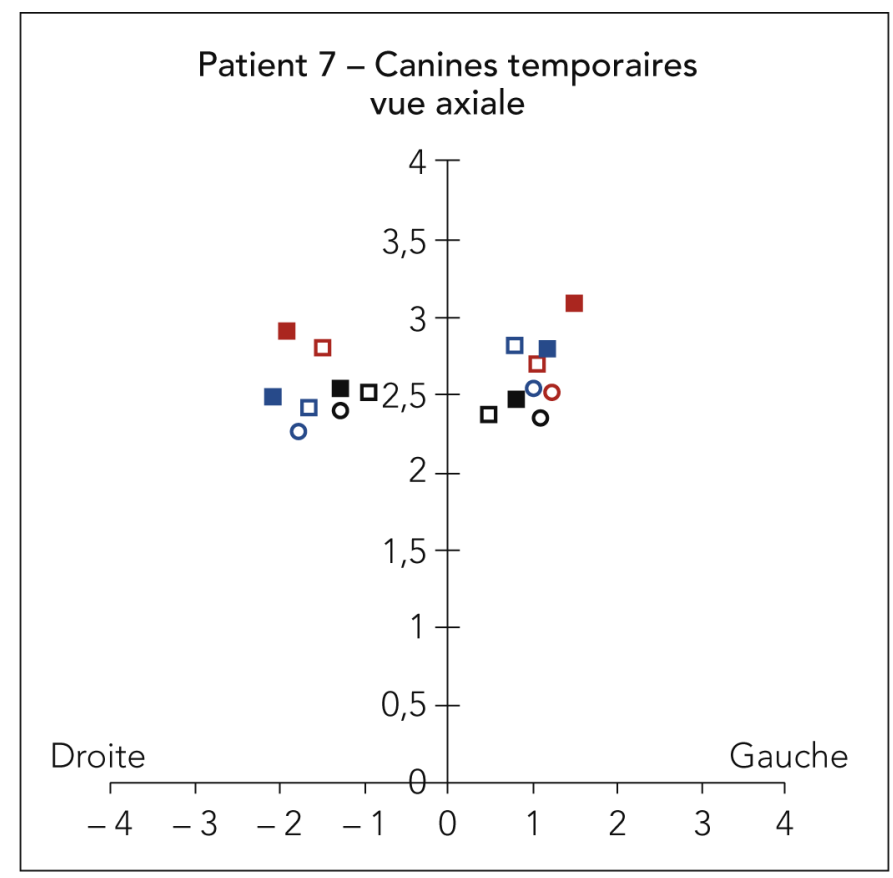

a

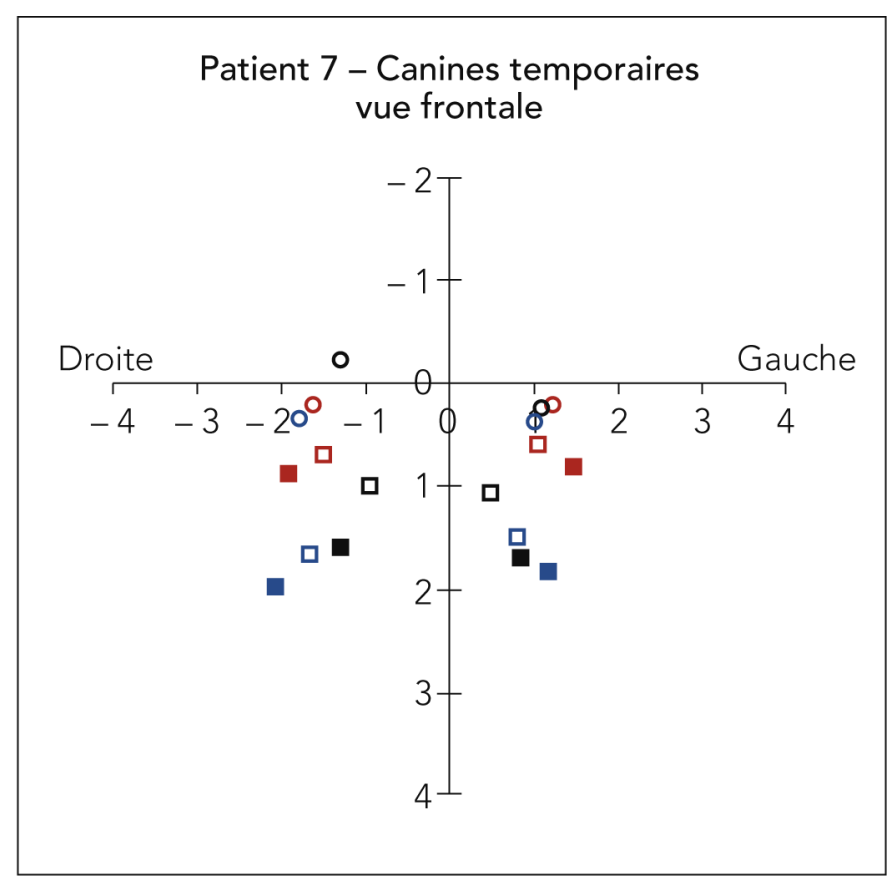

$\mathrm{b}$

Figure 7

Example of graphic representation of results, deciduous canines, patient $n^{\circ} 7$, (a) axial and (b) frontal view. Circle $=$ apex; empty square = neck; full square = canine tip; black = baseline situation at To; blue = pre-GPP situation at T1; red = post-GPP situation at T2.

\section{MATERIAL AND METHOD}

Patients were selected from among those in orthodontic treatment with Dr Vi Fane's team, in private practice or in Pr Ariane Berdal's rare diseases reference center and $\mathrm{Pr}$ Marie-Laure Boy-Lefèvre's functional unit in the Rothschild Hospital, and for whom primary surgery followed the 2000 Necker protocol. Inclusion criteria were: patient with bilateral CLP, and not purely alveolar cleft, and for whom native slice 3D data at 3 follow-up time points were available: baseline СВCT (or, in some cases, CT) (T0); pre-GPP CBCT at end of orthodontic preparation (T1); and post-GPP CBCT some 6 months after the second GPP (T2). In all, 7 patients with complete bilateral CLP were included in this retrospective study: 3 boys, 4 girls; mean age at start of orthopedic treatment, 4.5 years. Orthopedic preparation systematically used a rapid maxillary expander on dental splints followed by the Quad-Helix appliance. The maxillary arch was usually considered well-prepared for GPP if the intercanine distance $\mathrm{CC}^{\prime}$ was between 33 and $35 \mathrm{~mm}$. All maxillary CBCT scans were analyzed on Osirix ${ }^{\circledR}$ freeware. Measurements were taken from the digital tracing, with a posterior reference axis, through the two posterior 
palatine foramina. Measurements were made for the deciduous maxillary canines, definitive maxillary canines and deciduous maxillary second molars. To compare coronary and root expansion, three vertical landmarks were located: a coronary (cuspid) point, a cervical (neck) point, and a radicular (apex) point. In view of patient age, the radicular point was not studied in definitive canines:

\section{RESULTS}

Tables I to III present the movements obtained according to teeth, side and occlusion plane displacement. Mean post-GPP expansion (i.e., total final expansion) for the deciduous canines was $1.6 \mathrm{~mm}$ for the

\section{DISCUSSION}

\section{Degree of expansion}

The expansion achieved in this preliminary study was greater anteriorly than posteriorly, in agreement with other reports $3,14,25,30$. The position of the premaxilla was basically stable over time (no lateralization of the fragment). There may be several reasons for this. Natural maxillary growth includes rotation of the two maxillary hemispheres around their posterior attachment at the pterygoid processes $^{30}$. The absence of inter-incisor diastema, reported by Isaacson et al. ${ }^{14}$ in bilateral CLP, indicates that expansion is not in the inter-incisor suture, as in healthy subjects, as the median fragment is isolated from the continuity of the arch. The two anterior alveolar clefts may thus represent a double zone of expansion. as they are relatively high, they may be thought to reflect the basal effect induced by expansion. Three values, $x, y$ and $z$, were attributed to each landmark, to estimate the 3D variations of each point at different stages of treatment. Dental movement was presented graphically, on frontal (Fig. 7a) and axial view (Fig. 7b), using KaléidaGraph ${ }^{\circledR}$ software.

apex, $3.6 \mathrm{~mm}$ for the neck and $4.6 \mathrm{~mm}$ for the crown; for the deciduous second molars, $0.9 \mathrm{~mm}, 3 \mathrm{~mm}$ and $3.6 \mathrm{~mm}$ respectively; and for the definitive canines, $0.9 \mathrm{~mm}$ for the neck and $0.6 \mathrm{~mm}$ for the crown.

Clinically, this is not disadvantageous, since, as seen above, transverse maxillary defect is greater in the canines and worsens with time ${ }^{13}$.

\section{Nature of expansion}

Expansion was greater in the crown for deciduous canines and molars: i.e., in the direction of the increase in natural vestibular version; little variation was found in definitive canines. In agreement with the literature ${ }^{3,14,23,}$ and in contrast to what might be expected, expansion thus seems to be predominantly dento-alveolar rather than basal. According to Isaacson et al., facial resistance is increased in case of cleft, to compensate for tissular discontinuity. Thus, in bilateral cleft, where tissue 
Table I: Evolution between baseline and orthodontic preparation (TO to T1).

\begin{tabular}{|c|c|c|c|c|c|c|c|c|c|}
\hline \multirow[t]{2}{*}{ PATIENTS } & \multicolumn{3}{|c|}{ Deciduous canines } & \multicolumn{3}{|c|}{ Deciduous molars } & \multirow{2}{*}{$\begin{array}{c}\text { Definitive } \\
\text { canines }\end{array}$} & \multirow{2}{*}{$\begin{array}{l}\text { Occlusion } \\
\text { plane }\end{array}$} & \multirow{2}{*}{$\begin{array}{l}\text { Left/right } \\
\text { uniformity }\end{array}$} \\
\hline & Transverse & $\begin{array}{c}\text { Distal } \\
\text { translation }\end{array}$ & $\begin{array}{c}\text { Vestibular } \\
\text { version }\end{array}$ & Transverse & $\begin{array}{c}\text { Distal } \\
\text { translation }\end{array}$ & $\begin{array}{l}\text { Vestibular } \\
\text { version }\end{array}$ & & & \\
\hline Patient 4 & $\pi$ & $\begin{array}{l}\text { YES, esp. } \\
\text { right }\end{array}$ & NO & $\nearrow$ & YES ++ & YES & T & $\nearrow$ & NO \\
\hline Patient 5 & $\pi$ & NO & YES & $\nearrow$ & YES & YES++ & slight & $\rightarrow$ & YES \\
\hline Patient 6 & $\rightarrow$ & & & $\nearrow$ & YES & $\begin{array}{l}\text { rather } \\
\text { lingual } \\
\text { version }\end{array}$ & $\searrow$ slight & $\rightarrow$ & YES \\
\hline Patient 7 & $\pi$ & NO & YES++ & $\pi$ & YES & YES++ & त & $\searrow$ & NO \\
\hline
\end{tabular}

Green: transverse increase and/or improvement; red: transverse decrease and/or aggravation; blue: stable.

Table II: Evolution between baseline and post-surgical phase (T0 to T2).

\begin{tabular}{|c|c|c|c|c|c|c|c|c|c|}
\hline PATIENTS & Transverse & $\begin{array}{c}\text { Distal } \\
\text { translation }\end{array}$ & $\begin{array}{l}\text { Vestibular } \\
\text { version }\end{array}$ & Transverse & $\begin{array}{c}\text { Distal } \\
\text { translation }\end{array}$ & $\begin{array}{l}\text { Vestibular } \\
\text { version }\end{array}$ & $\begin{array}{c}\begin{array}{c}\text { Definitive } \\
\text { canines }\end{array} \\
\text { Transverse }\end{array}$ & $\begin{array}{l}\text { Occlusion } \\
\text { plane }\end{array}$ & $\begin{array}{l}\text { Left/right } \\
\text { uniformity }\end{array}$ \\
\hline Patient 1 & त & YES, left & $\begin{array}{l}\text { YES, } \\
\text { left }\end{array}$ & T & NO & $\begin{array}{l}\text { YES++ } \\
\text { esp.left }\end{array}$ & IIII & T & NO \\
\hline Patient 7 & $\pi$ & $\begin{array}{l}\text { YES, } \\
\text { right }\end{array}$ & YES++ & r & YES & YES++ & T & $\nearrow$ & NO \\
\hline
\end{tabular}

Green: transverse increase and/or improvement; red: transverse decrease and/or aggravation; blue: stable.

Table III: Evolution between orthodontic preparation and post-surgical phase (T1 to T2).

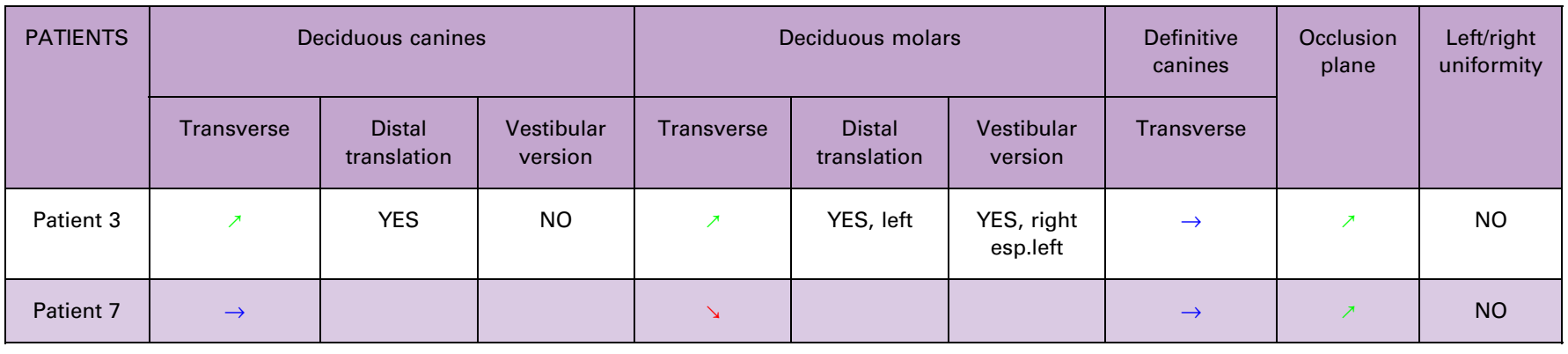

Green: transverse increase and/or improvement; red: transverse decrease and/or aggravation; blue: stable. 
discontinuity is greatest and scarareas most numerous, movement is more restricted and dento-alveolar compensation predominates over the basal effect, as compared to unilateral CLP ${ }^{30}$. Although the intrinsic nature of the cleft cannot be altered, intervention to correct the transverse dimension should be early, as, during growth, expansion increasingly induces dento-alveolar compensation.

\section{Relapse}

In all patients, the transverse direction is considered especially subject to relapse. By interposing osseous material between the distracted maxillary segments, GPP may seem to be a means of maintaining expansion. However, this bone filling is purely anterior. In 1964, Matthews and Grossmann ${ }^{15}$ concluded that orthopedic expansion followed by GPP was associated with no relapse. This was in contradiction to more recent reports, systematically finding a general tendency to

\section{PERSPECTIVES}

Taken together, the present retrospective findings provide interesting preliminary information; however, statistical analysis is not possible at this stage.

Like other teams studying bilateral cleft, we were unable to constitute a powerful sample. Bilateral clefts are the most rare. Moreover, to achieve homogeneity, not all patients seen in the rare diseases reference center were included, unless surgery had been performed by $\operatorname{Pr}$ Vazquez's relapse $3,18,22,23,32$, even with bone graft $^{18,22,23,32}$.

The present results seem to show that expansion is maintained or even increases. There may be several reasons for this. The orthodontic expansion device, fitted ahead of GPP, is left in the mouth well after healing; a contention effect may thus minimize relapse. Natural transverse growth may also help maintain expansion. The type of expansion does not seem to be a predictive factor: rapid expansion is reputed to have skeletal and thus more stable impact, but slow expansion is less subject to resistance from surrounding tissue, allowing more physiological bone formation that is less at risk of relapse ${ }^{3}$. It should, moreover, be borne in mind that the clinician can reactivate the Quad-Helix appliance that is left in contention if need be. Further study is needed of the stability induced by grafting, which cannot alone maintain expansion, as demonstrated by Robertson and Fish ${ }^{22}$.

team following the protocol adopted in 2000.

Treatment duration for bilateral cleft posed a further problem. The interval between two GPPs was about 6 months, so that the final CBCT scan (T2) implies a much longer observation period than in unilateral CLP. For this reason, CBCT scans were not available in all cases, especially in DiCOM format. Continuing the study, however, should flesh out these preliminary conclusions, 
including new patients, with longer follow-up, notably at the time of definitive canine eruption.

Radiology data collection also involved problems. The CВCT scans were intended for use at two sites, Rothschild and Necker, and priority was given to the surgery for which they had been prescribed. This geographic dispersion of data hampered collection; documents were sometimes in the hands of the patient's parents.

\section{CONCLUSION}

The initial results of the present study show that expansion was principally dento-alveolar by coronary version, rather than skeletal as we had supposed. Also, it was greater for canines than molars. Finally, the findings regarding relapse suggest that expansion is maintained, on condition that the expansion apparatus be kept in contention for a relatively long time.

The present report is part of a larger-scale and longer-term study
Furthermore, the radiology reports were not systematically accompanied by a CD-ROM with the native slices. This was especially the case for older patients and older examinations. The radiology films were in such cases analyzable clinically, which was the original objective, but not for the purposes of the present study, leading to further exclusions even when all three CBCT scans had been performed. characterizing 3D dento-alveolar movement in both uni- and bi-lateral CLP, and also assessing the bone volume required and actually grafted and its quality and quantity after graft consolidation. Ongoing standardization of radiology documents will contribute to achieving these objectives.

Conflicts of interest: The author declares no conflict of interest.

\section{BIBLIOGRAPHY}

1. Avery JK, Chiego DJ. Essentials of oral histology and embryology: a clinical approach. St. Louis, Mo: Mosby Elsevier, 2006.

2. Berkowitz S. Cleft lip and palate: [diagnosis and management]. New York, NY: Springer, 2006.

3. Bishara SE, Staley RN. Maxillary expansion: Clinical implications. Am J Orthod Dentofacial Orthop 1987;91(1):3-14.

4. Bjork A, Skieller V. Growth in width of the maxilla studied by the implant method. Scand J Plast Reconstr Surg 1974;8(1-2):26-33.

5. Bjork A, Skieller V. Growth of the maxilla in three dimensions as revealed radiographically by the implant method. Br J Orthod 1977;4(2):53-64.

6. Camporesi M, Baccetti T, Marinelli A, Defraia E, Franchi L. Maxillary dental anomalies in children with cleft lipand palate: a controlled study: Dental anomalies in CLP subjects. Int J Paediatr Dent 2010;20(6):442-450. 
7. Captier G, Bigorre M, Mattei L, Delestan C, Montoya P. La greffe osseuse secondaire dans les fentes labiomaxillo-palatines totales: modalités techniques etindications à propos de 62 greffes. Ann Chir Plast Esthét 2003;48(1):20-30.

8. Chancholle AR, Saboye J, Tournier JJ. Prise en chargedes fentes labio-palatines par I équipe du docteur Chancholle à Toulouse. EMC - Ann Chir Plast Esthét 2002; 47(2):92-105.

9. Dahl E. Transverse maxillary growth in combined cleft lip and palate. A longitudinal roentgencephalometric study by the implant method. Cleft Palate J 1979;16(1):34-41.

10. Delaire J. General considerations regarding primary physiologic surgical treatment of labiomaxillopalatine clefts. Oral Maxillofac Surg Clin N Am 2000;12(3):361-378.

11. Guo J, Li C, Zhang Q, Wu G, Deacon SA, Chen J, Hu H, Zou S, Ye O. Secondary bone grafting for alveolar cleft in children with cleft lip or cleft lip and palate. Cochrane Database Syst. Rev 2011.

12. Halpern RM, Noble J. Location and presence of permanent teeth in a complete bilateral cleft lip and palate population. Angle Orthod 2010;80(3):591-596.

13. Heidbuchel KL, Kuijpers-Jagtman AM. Maxillary and mandibular dental-arch dimensions and occlusion inbilateral cleft lip and palate patients form 3 to 17 years of age. Cleft Palate-Craniofacial J Off Publ Am Cleft Palate-Craniofacial Assoc 1997;34(1): 21-26.

14. Isaacson RJ, Murphy TD. Some Effects Of Rapid Maxillary Expansion In Cleft Lip And Palate Patients. Angle Orthod 1964;34(3):143-154.

15. Matthews D, Grossmann W. Restoration of the collapsed maxillary arch by rapid expansion and bone grafting. Cleft Palate J 1964;30:430-440.

16. Morand B, Raphael B. [Bilateral cleft lip and palate. Anatomic and clinical characteristics and therapeutic results]. Orthod Fr 2004;75(3):243-251.

17. Mossey P, Little J (2002) Epidemiology of oral clefts:an international perspective. In: Wyszynski DF (eds) Cleft lip and palate. From origin to treatment. Oxford University Press.

18. Nicholson PT, Plint DA. A long-term study of rapid maxillary expansion and bone grafting in cleft lip and palate patients. Eur J Orthod 1989;11(2):186-192.

19. Pavy B, Talandier C, Huart J, Majourau-Bouriez A, Mitrofanoff M. Fentes labiales et palatines : la prise en charge de l'équipe de Saint-Vincent-de-Paul. EMC - Ann Chir Plast Esthét 2002;47(4):280-284.

20. Picard A, Galliani E, Soupre V, et al. Calendrier et protocole interventionnel des fentes labiopalatines au sein du Service de chirurgie maxillo-faciale et plastique de l'Hôpital d'Enfants Trousseau (AP-HP, Paris). Rev Orthopédie Dento-Faciale 2011;45(3): 291-299.

21. Qureshi WA, Beiraghi S, Leon-Salzar V. Dental anomalies associated with unilateral and bilateral cleft lip and palate. J Dent Child Chic III 2012;79(2):69-73.

22. Robertson NR, Fish J. Some observations on rapidexpansion followed by bone grafting in cleft lip and palate. Cleft Palate J 1972;9(3):236-245.

23. Rune B, Sarnas KV, Selvik G, Jacobsson S. Movement of maxillary segments after expansion and/or secondary bone grafting in cleft lip and palate: a roentgen stereophotogrammetric study with the aid of metallic implants. Am J Orthod 1980;77(6):643-653.

24. Russell KA, McLeod CE. Canine eruption in patients with complete cleft lip and palate. Cleft Palate-Craniofac J 2008;45(1):73-80.

25. Sandikciolu M, Hazar S. Skeletal and dental changes after maxillary expansion in the mixed dentition. Am J Orthod Dentofacial Orthop 1997;111(3):321-327.

26. Shaw WC, Semb G, Nelson P, Brattström V, Mølsted K, Prahl-Andersen B, Gundlach KK. The Eurocleft project 1996-2000: overview. J Craniomaxillofac Surg 2001;29(3): 131-140; discussion 141-142. 
27. Da Silva Filho OG, Vallafares Neto J, Capelloza Filho L, de Souza Freitas JA. Influence of lip repair oncraniofacial morphology of patients with complete bilateral cleft lip and palate. Cleft Palate-Craniofac J 2003;40(2):144-153.

28. Talmant JC, Lumineau JP, Rousteau G. Prise en chargedes fentes labio-maxillo-palatines par l'équipe du docteur Talmant à Nantes. EMC - Ann Chir Plast Esthét 2002; 47(2):116-125.

29. Talmant J-C, Lumineau J-P. Fentes labiales et palatines. Traitement primaire. EMC Tech Chir - Chir Plast Reconstr Esthét 2011;6(3):1-26.

30. Tindlund RS, Rygh P, Boe OE. Intercanine widening and sagittal effect of maxillary transverse expansion in patients with cleft lip and palate during the deciduous and mixed dentitions. Cleft Palate-Craniofac J 1993;30(2):195-207.

31. Tortora C, Meazzini MC, Garattini G, Brusati R. Prevalence of Abnormalities in Dental Structure, Position, and Eruption Pattern in a Population of Unilateral and Bilateral Cleft Lip and Palate Patients. Cleft Palate Craniofac J 2008;45(2):154-162.

32. Toscano D, Baciliero U, Gracco A, Siciliani G. Long-term stability of alveolar bone grafts in cleft palate patients. Am J Orthod Dento facial Orthop 2012;142(3):289-299.

33. Trotman CA, Ross RB. Craniofacial growth in bilateral cleft lip and palate: ages six years to adulthood. Cleft Palate-Craniofac J 1993;30(3):261-273.

34. Wu T-T, Chen PKT, Lo LJ, Cheng MC, Ko EW. The characteristics and distribution of dental anomalies in patients with cleft. Chang Gung Med J 2011;34(3):306-314. 